\title{
Block-Movements in the Boso Peninsula (Japan)
}

PROF. N. MIYABE has recently published two remarkable papers on the movements of crustblocks (Earthq. Res. Inst. Bull., vol. 9, pp. 256-272, $407-422 ; 1931)$. It is clear that if a crust-block is tilted as a whole, there must exist a simple geometrical relation between the amounts of tilting in two different directions. Conversely, if this relation is satisfied by the tilts along neighbouring pairs of lines, Prof. Miyabe regards the lines as lying on the same block. The papers are concerned with the crustblocks of the Boso peninsula on the east side of Sagami Bay. The first survey of the district was made in 1898, the line of levelling being near the coast. It was repeated in 1924, shortly after the great earthquake of Sept. 1, 1923, and again in 1931, and the two papers refer to the displacements that occurred during the intervals between the surveys.

In the accompanying map (Fig. 1), the dotted lines represent the probable boundaries of the crust-blocks and the arrows denote the magnitudes and directions of tilting of the different blocks. The boundaries were drawn without any reference to geological maps, but several of them were found to coincide approximately with discontinuities in geological structure. These are shown as continuous lines. One of them is a well-marked tectonic line to the north of Kamo. gawa, and it will be noticed how different are the directions of tilting of the blocks to the north and south of this line.

The figures on the map denote the mean uplift of each block in inches between 1898 and 1924. It will be seen that there are three groups of blocks, in each of which the uplifts are approximately the same. In the south-west corner of the peninsula, they lie, as a rule, between 47 in. and 51 in., with two exceptional amounts of $55 \mathrm{in}$. and $61 \mathrm{in}$. To the north and east of this lies a group in which the uplift is confined between 23 in. and 31 in.; and, still farther, a third group in which the movements are between 8 in. and 12 in., with two exceptions of $18 \mathrm{in.}$ and $22 \mathrm{in.}$

In the second paper, the changes of level that occurred between 1924 and 1931 are compared with those of the earlier interval. The curves representing them show that, on the whole, the vertical movement was reversed. For example, a block elevated by 45 in. in the first interval was depressed by nearly 4 in. in the second. Though the constituent blocks

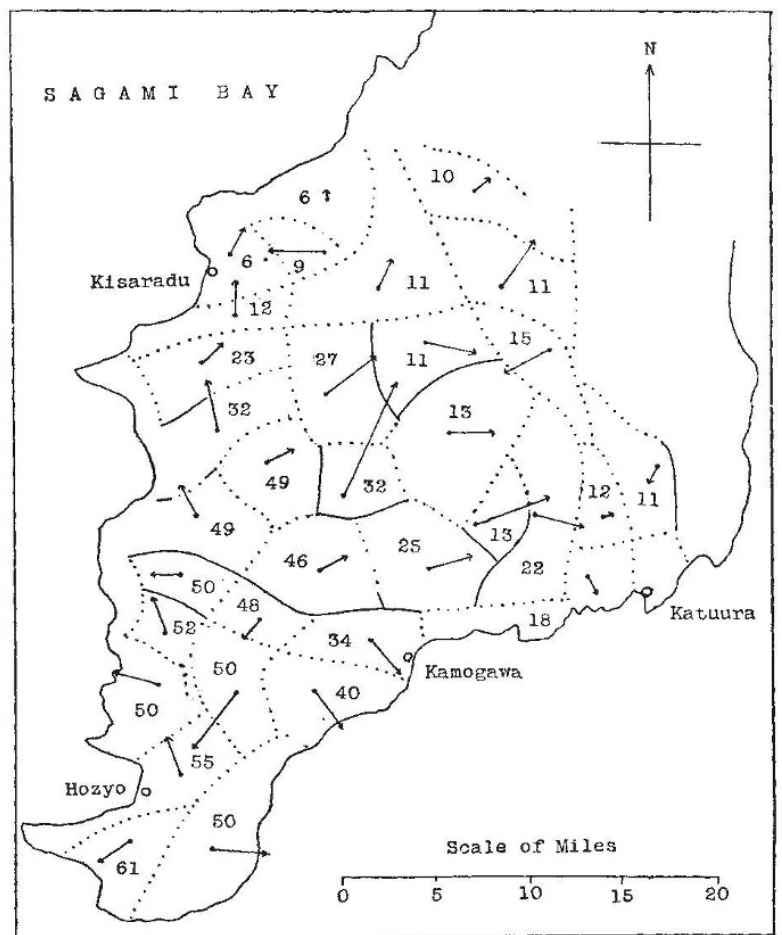

FIG. 1.

show a certain independence of movement, it $\mathrm{w}$ ould seem that the Boso peninsula underwent a ge neral tilting towards the north-east in the first inte 1val, and a return tilting towards the south-west in the second.

\section{Preservation of Italian Folklore}

$\mathrm{I}^{\mathrm{N}}$ Italy under the Fascist government every encouragement has been given to movements which quicken national self-consciousness. Those who value tradition, whether for sentimental or for scientific reasons, will applaud the efforts of the Opera Nazionale Dopolavoro (The Workers' Leisure Hours Institute) to preserve the festivals, music, and dancing of the folk, which are endangered by the industrial development of the country. Now that Russia no longer pays heed to her saints, no country in Europe is so rich as Italy in festivals, and nowhere have they been celebrated with more ritual and greater enthusiasm. It would have been a calamity had they been allowed to lapse. This probably would have been the fate of many, had it not been for the "Dopolavoro". Their continued existence now seems assured.

An excellent account of the work of the Institute in this field, for which the president, S. Enrico Beretta, is responsible, has been published recently.* The first section of the book, however, is devoted to a list of

* "Costumi, musica, danze e feste popolari italiane." Pp. 218 Roma: Editione Opera Nazionale Dopolavoro, 1931.) 10 lire. the feste which are observed in the various towns and districts of Italy. They are arranged calendrically, and brief descriptions of the essential features are given in each case. Many are illustrated by excellent photographs.

The feste are usually observed on the feast-day of the patron saint of the district, or on some festival of the Church; but pagan affinities are generally fairly easy to detect. The central feature is normally a procession, in which the image of the saint is carried round the district in a cart or on a platform. Sometimes the cart is buried in flowers; sometimes the place of the saint and cart is taken by obelisks or gigantic towers, such as the Ceri of Gubbio or the Gigli of Nolo (Naples). It is a reasonable conclusion that in ancient days the gods were carried along these same ways to purify the lands and secure the fertility of the fields of their votaries. At Easter the Scoppio del Carro of Florence betrays clearly the purpose of the rite. A mechanical dove released from the High Altar ignites the squibs set around the carro as it stands before the cathedral. A successful explosion is hailed as a sure index of abundance in the coming 